\title{
Households' Preference for Local Rice in the Upper East Region, Ghana
}

\author{
Dennis Sedem Ehiakpor, ${ }^{1}$ Justice Apumbora, ${ }^{1}$ \\ Gideon Danso-Abbeam, ${ }^{1,2}$ and William Adzawla ${ }^{3}$ \\ ${ }^{1}$ Department of Agricultural and Resource Economics, University for Development Studies, Tamale, Ghana \\ ${ }^{2}$ Discipline of Agricultural Economics, University of KwaZulu-Natal, P. Bag X01, Scottsville 3209, Pietermaritzburg, South Africa \\ ${ }^{3}$ Universite Cheikh Anta Diop, WASCAL GRP-CCE, BP 5683, Dakar-Fann, Senegal
}

Correspondence should be addressed to Gideon Danso-Abbeam; dansoabbeam@uds.edu.gh

Received 11 June 2017; Revised 17 September 2017; Accepted 22 October 2017; Published 15 November 2017

Academic Editor: Ayman Suleiman

Copyright (C) 2017 Dennis Sedem Ehiakpor et al. This is an open access article distributed under the Creative Commons Attribution License, which permits unrestricted use, distribution, and reproduction in any medium, provided the original work is properly cited.

\begin{abstract}
Considering the increasing demand in the rice industry, the study was undertaken to determine the factors influencing household preference for locally produced rice in the Upper East Region, Ghana. Primary data was obtained from a sample of 180 households with the aid of a structured questionnaire. Probit model and Kendall's coefficient of concordance were used to analyze the data. Significant socioeconomic factors include income, age, sex, and marital status, whereas the quality factors such as the absence of foreign materials, packaging, and aroma were also significant determinants of preference for local rice. The top three traits consumers consider in their choice for local rice were good-looking grains, excellent packaging, and absence of foreign materials in the rice. There was an evidence of an increased preference for quality local rice. Hence, increased investment in the rice value chain, particularly the processing stage where quality standards remain the topmost priority, will help boost consumers' confidence in the local rice market.
\end{abstract}

\section{Introduction}

Rice is one of the crops that is cultivated and consumed in almost all countries across the globe. It is no surprise that rice was part of the green revolution crops that has led to the success of most Asian countries today. However, while consumption per capita is declining in some parts of Asia, it has been increasing considerably in Sub-Saharan Africa (SSA) since 1995 compared to any other continent [1]. In 2013, the production of rice in the Sub-Saharan Africa was estimated at 22.4 million tonnes [2], which is far below the consumption needs. As reported by [2-4], although rice production in SSA has increased considerably over the past five decades, consumer demand has outpaced production supply resulting in imports. This is partly because the share of imported rice in total consumption in SSA has grown substantially from $2 \%$ to about $43 \%$ over the past five decades [5]. Moreover, in 2011, almost one-third (11.8 million tons) of the rice traded on the world market was imported by the Africa continent compared with about 0.5 million in 1961 [6]. This is at an alarming cost of over US $\$ 4.3$ billion per year, an amount which otherwise could have been used in other areas of development [7]. The slow growth in domestic rice production has been attributed to the low yield being achieved by rice farmers while the increase in rice consumption can partly be attributed to a combination of population, urbanization, changing consumer preference, and economic advancement $[1,8,9]$.

In Ghana, rice has become a major staple crop in recent times although the crop has been cultivated for several years. It is an essential food for both rural and urban dwellers and is gradually taking over from traditional crops, mainly root, tuber, and cereals like maize and millet. Among cereals in Ghana, the per capita consumption of rice is second to maize. It has been estimated that 24 kilograms of rice are consumed per person each year [10]. Kwofie et al. [11] estimated that per capita rice consumption would increase to 68 kilograms per head by 2018 and attributed the increasing consumption to rising urban population. The high consumption of rice, 
especially in the urban regions, is perhaps, due to the relative easiness of rice preparation compared to most of the local foods [11]. What this means is that domestic rice production must be fast growing; otherwise, the country may have no option than to continue its importation. Unlike other products, the case of local rice is complicated as it is not entirely a production problem but also processing and consumption problem. It is asserted that the handling of the local rice is arduous and requires energy from wood which has its negative effects on human health and the climate [11]. Dogbe et al. [12] argued that improving rice production in the country could directly contribute to foreign currency saving and improve farmers' income.

Like most other crops, rice production is mostly done by smallholder farmers, and it is a source of livelihood for these farmers. Several efforts have been made by various governments to increase the production of rice in the country. However, the provision of technical advice and the formulation of suitable policies designed to make the nation selfsufficient have not yet yielded the desired results. The smallscale farmers who dominate the local rice production lack access to premium varieties that are demanded by the market. Several rice varieties are grown on the same piece of land leading to a mix-up of the rice output resulting in poor quality of rice and, subsequently, attracting low prices. With only less than $5 \%$ of Ghana's agricultural land being irrigated, rice is primarily produced under rain-fed conditions [13]. Most of the rice seeds are of low quality and with mixed varieties resulting in uneven maturity periods and wide variations in size. Among others, these reasons account for the wide differences in the quality of the local rice compared to the imported rice. There is also a general inadequacy of the right threshing platforms and storage facilities for rice farmers [14]. On their part, Addison et al. [15] argued that despite the yield gains in rice production, little has been done on postharvest management practices which have limited the competitiveness of the local rice industry. The result is high postharvest losses and copious amounts of broken grains after straight milling.

Consumers in Ghana pay attention to grain quality and favourable pricing in their choice of rice types. According to Danso-abbeam et al. [16], apart from price and grain characteristics that influence consumers' rice preference, other socioeconomic factors could explain consumers' preference for rice in Ghana and other parts of the world. One of the main challenges in Ghana, therefore, is how to produce sufficient and affordable domestic rice that suits the preferences of its fast-growing population. Ghana's domestically produced rice must compete with imported rice which is often of higher quality regarding visual appearance and grain characteristics such as grain size, colour, and aroma. For the success of improving domestic rice consumption, it is necessary that the attributes of the rice that has a link with its preference are understood. The promotion of domestic rice production and consumption has been one of the new transformational agenda adopted by the government of Ghana. It is a fact that rice importation in addition to other goods has led to a high import bill, negatively affecting the balance of payment of the country [17]. The most obvious way to reduce the import bill is to invest and promote the consumption of domestically produced rice. Consumers all over the country have varying product preferences that are mostly guided by their perceptions, price, and the utility they derived from these commodities. This means that some factors predetermine the consumption of locally produced rice. It is only when the peculiar case of locally produced rice is identified, developed, and resolved that the government's intentions and initiatives of reversing the import bill on rice would be achieved. Therefore, the objective of this study is to identify the factors influencing consumers' preference for local rice in the Upper East Region of Ghana. In addition to previous studies on domestic rice consumption in the region, this could provide relevant information for reviving consumer demand for local rice.

1.1. Consumer Behaviour and Preference for Local Rice. The consumer behaviour model postulated by Lancaster [18] states that products are consumed for the characteristics they possess, other than the product itself, and are associated with consumer preferences or utility. For instance, in the case of rice, the quality characteristics have vital price based implications regarding incentives for producers and consumers. That is, poor perception or consumer behaviour relating to local rice has poorly affected its production and consumption. However, as noted by Mottaleb and Mishra [19], consumer preference for rice quality is heterogeneous, and there is no unique method to examine the quality of the rice grain. It is generally recognized that there is a preference for imported rice and so local rice has a competitive disadvantage against imported rice [20]. Factors such as product quality, price, and availability favour the Ghanaian consumers' preference for foreign products. The general notion among some Ghanaians has been that locally manufactured goods are inferior to imported or foreign manufactured goods regarding quality. This has also been reported by Mottaleb and Mishra [19] that rice grain quality can be "superficial" and can be altered by labelling and packaging, which means that consumers have to be extra vigilant on their choices if they want to attain the desired utility from such goods. Consumers often express their preferences for product quality by paying a premium for the product with the desired characteristics. These premiums give producers an incentive to improve the product quality and quantity, consequently enhancing the welfare of both the consumer and the producer. Consumers are faced with tradeoffs in their purchasing decisions since income is limited and choices are numerous. When making choices, consumers must combine budget constraints and preferences. Budget constraints are determined by both the income of the consumer and the relative prices of the products. On the other hand, products are differentiated based on the characteristics they possess. It is assumed that once consumers recognize their peculiar preferences, they are prepared to pay more for variants that are better suited to their tastes [21]. This means that whatever risk the producer takes in producing a product (in this case to grow rice), it is ultimately the consumer preference that decides its success in the market. According to Diako et al. [22], consumers are often concerned about the quality and price of the commodity when they make a 
TABLE 1: Categories of Rice traits and their description elicited from the respondents.

\begin{tabular}{lc}
\hline Traits category & Respondents' description of rice characteristics \\
\hline Cleanness & No stones, no dead rice, no impurities \\
Taste & Very delicious, tasteful, sweet \\
Nutritional benefits & High nutritional value, nonfattening \\
Good-looking grains & Uniform size and shape, long-grain, nonbroken grains, whitish in colour \\
Aroma & Perfumed-like, unique rice aroma, smells good \\
Texture & Soft, smooth, nonsticky \\
Ease of cooking & Does not need excessive water, does not take longer time to cook \\
Packaging & In a clean well-designed pack, well-sealed \\
Relative price & competitive price, equal or lower than the imported price \\
Volume of expansion & Increase in quantity after cooking \\
\hline
\end{tabular}

purchase. In Ghana, and in most other African countries, the imported rice became a consumer choice due to its cleanliness and swelling capacity, taste, availability, and grain size/shape. Not only are these driving household demand but also restaurants and fast food industries have resorted to imported rice to meet their customers' choice and boost their businesses.

\section{Methodology}

2.1. Study Area and Methods of Data Collection. The Upper East Region of Ghana is located in the north-eastern corner of the country between longitudes $0^{\circ}$ and $1^{\circ}$ West and latitudes $10^{\circ} 30^{\prime \prime} \mathrm{N}$ and $11^{\circ} \mathrm{N}$ and bordered by Burkina Faso to the north and Togo to the east and the west by Upper West region and the south by Northern region. The capital is Bolgatanga, usually called Bolga. The land is relatively flat with few hills to the East and Southeast. The region's soil is upland soil mainly developed from granite rocks. It is shallow and low in soil fertility, weak with low organic matter, and predominantly coarse textured and susceptible to erosion. The center of population of the Upper East Region is located in its capital, Bolgatanga. The population is primarily rural (79\%) and scattered in dispersed settlements. In 2010, its population was 920,089 representing $4.9 \%$ of Ghana's total population.

A multistage sampling procedure was used in selecting the respondents. First, the study chose purposively the Upper East Region due to the importance of rice production and consumption in the region. It is the third highest producer of rice in Ghana [10]. In the second stage, a simple random sampling technique was used to select five districts from the 13 districts of the region. Three towns were then selected from each selected district. Finally, 12 households from each selected town were selected, making a total of 180 sampled households. Data collected was from primary source through the administration of the structured questionnaire. The data collected provides information on the socioeconomic characteristics of the respondents, rice preference, and constraints to local rice consumption.

2.2. Analytical Technique. The data was analyzed using both qualitative and quantitative methods. Descriptive statics such as graph, percentages, and means were used while Probit regression model was used to identify factors influencing consumers' preference for local rice. To examine factors inhibiting consumers preference for local rice, the study assessed some similarities of consumers' preference for rice by using some quality traits (based on consumers' responses) to describe the characteristics they expect from a quality domestically produced rice. Following Fitzgerald [23] and Diagne et al. [24], the study defined rice quality within the context of physical, nutritional value, cooking behaviour, sensory characteristics, good-looking grains, and packaging. These characteristics are grouped into ten main categories of traits. Consumers were then asked to rank which they consider the most, second most, and third most important traits that they consider in their preference for the local rice. Table 1 summarizes the category of traits and how consumers describe those traits. Then Kendall's coefficient of concordance was used to measure the level of agreement among the consumers.

2.2.1. Consumer Theory and the Probit Model. Consumer preference is defined as the subjective (individual) tastes, as measured by the utility of various bundles of goods. In practice, preference permits consumers to assign importance to some products than others. The theory of consumer choice is the branch of microeconomics that relates preferences to consumption expenditures and consumer demand curves. It analyzes how consumers maximize the desirability of their consumption as measured by their choices subject to limitations on their expenditures, by maximizing utility subject to a consumer budget constraint.

Consumer behaviour theories together with models derived from such theory are proposed to address the concepts of consumer preference, utility maximization, and demand functions [25]. The new consumer demand theory postulates that consumers make choices not on the simple marginal rate of substitution between goods, but based on preferences for attributes of these products. This approach to consumer demand theory provides that consumers derive utility from attributes of goods rather than the good itself. However, attributes of goods are not always valued in real markets. Economists have over the years developed methods 
for estimating the value of such nonmarket goods and services using stated preference and revealed preference methods. These methods rely on observable behaviour to decide how much something is worth to an individual even though it is not traded in markets [26]. Among the various methods used to analyze such consumer decision is the Probit or logit model.

A Probit model is one of the binary choice models that have extensively been used in literature to examine binary outcomes. It is a random utility model where consumers choose the alternative that gives them the maximum utility. For instance, in this study, the individual's or household's preference for local rice is dichotomous, involving two mutually exclusive alternatives. An individual or household either mostly prefers a local rice or mostly prefers imported rice based on the expected utility from local and imported rice. The framework for such analysis has its roots in the threshold theory of decision-making in which a reaction occurs only after the strength of a stimulus increases beyond the individual's reaction threshold [27]. This implies that every individual or household, when faced with a choice, has a reaction threshold influenced by several factors. Therefore, a consumer would prefer local rice if the expected utility from this rice is higher than that of imported rice; otherwise, the consumer would prefer imported rice.

Mathematically, let's assume that

$$
I^{*}{ }_{i}=\beta_{i} X_{i}
$$

where $I^{*}{ }_{i}$ is an unobservable utility and $X_{i}$ is a vector of factors influencing utility of the $i$ th observation. However, the unobserved utility is related to the observable $Y=1$ if the consumer's choice is positive and $Y=0$ if a negative choice. In this study, the consumer prefers local rice $(Y=1)$ and imported rice $(Y=0)$, respectively. The Probit model assumes that, apart from the observed values of 0 and 1 for the dependent variable $Y$, there is a latent continuous variable $Y^{*}$ that determines the value of the dependent variable $Y$. The dependent variable $Y^{*}$ is a dichotomous which represents the preference condition of the consumers' taking the values of 1 for local rice and 0 for imported rice. $Y^{*}$ is, therefore, assumed to be specified as follows:

$$
\begin{gathered}
Y^{*}=\beta_{0}+\sum_{k=1}^{K} \beta_{k} X_{k}+\varepsilon_{i}, \\
Y_{i}=Y^{*} \quad \text { if } Y^{*}>0, \\
Y_{i}=0 \quad \text { if } Y^{*} \leq 0,
\end{gathered}
$$

where $X_{k}$ is a vector of variables influencing consumer's preference for local rice, $\beta_{k}$ is a parameter to be estimated, and $\varepsilon_{i}$ is an error term.
Empirically, the model estimated to examine the factors influencing consumers' preference for local rice is given as

$$
\begin{aligned}
\text { preference }= & \beta_{0}+\beta_{1} \text { income }+\beta_{2} \text { age }+\beta_{3} \text { age } \\
& - \text { squared }+\beta_{4} \text { sex }+\beta_{5} \text { maritalstatus } \\
& +\beta_{6} \text { householdsize }+\beta_{7} \text { education } \\
& +\beta_{8} \text { grainsize }+\beta_{9} \text { texture } \\
& +\beta_{10} \text { cleannness }+\beta_{11} \text { aroma } \\
& +\beta_{12} \text { packaging }
\end{aligned}
$$

where preference is dichotomous, 1 if the consumer (household head) mostly prefers local rice and 0 if he/she mostly prefers imported rice. Income is the total household income, age is the age of the household head in years, and age squared is the multiplication of age by itself; sex is a dummy that takes on 1 for females and 0 for males; marital status is a dummy and described as 1 for married and 0 for otherwise; household size is the total number of people in the household sharing and pooling consumption and production resources together; education is the total number of years of formal education a respondent had; grain size is dummy, 1 for good grain size quality including whole grain (nonbroken) and 0 for poor grain size including broken grain; texture is 1 if the consumer considers the rice texture (in terms of softness, smoothness, and nonstickiness) and 0 if otherwise; cleanness is 1 if a consumer perceives local rice as having foreign materials such as pebbles and 0 if otherwise; aroma is described as 1 for respondents who consider aroma from the rice brand in their decision and 0 if otherwise, and package is 1 if the nature of packaging of rice is considered in the purchase of rice and 0 if otherwise.

2.2.2. Kendall's Coefficient of Concordance. Kendall's coefficient of concordance is one of the most frequently used nonparametric methods for assessing a set of observation. This is widely used perhaps due to its ability to provide both the ranks of the observations and the level of agreement among the set of observations. In its application, a list of constraints is provided to the respondents and the individual respondent is allowed to provide his/her ranking of the constraint, depending on most important to less important or vice versa. In this study, a list of rice traits (as described in Table 1) is presented to the respondents and they were asked to rank them in order of importance in terms of preference. The sum of ranks is then provided but, in most empirical studies, it is common to observe the mean of ranks. Kendall's coefficient of concordance $(W)$ is given as [28]

$$
W=\frac{12 S}{p^{2}\left(n^{2}-n\right)}-p^{t},
$$

where $p$ is the number of observations, $n$ is the number of rice traits being ranked, $S$ is the sum of squares, and $t$ indicates correction for tie. The value of $W$ is tested using the chi square, $X^{2}=p(n-1) W$, with the null hypothesis of no agreement in the ranks of traits as provided by the 
TABLE 2: Socioeconomic characteristics of respondents.

\begin{tabular}{|c|c|c|}
\hline Description & Frequency & Percentage \\
\hline \multicolumn{3}{|l|}{ Sex } \\
\hline Male & 31 & 17.2 \\
\hline Female & 149 & 82.8 \\
\hline \multicolumn{3}{|l|}{ Age } \\
\hline $20-29$ & 23 & 12.8 \\
\hline $30-39$ & 46 & 25.6 \\
\hline $40-49$ & 62 & 34.4 \\
\hline $50-59$ & 34 & 18.9 \\
\hline $60+$ & 15 & 8.3 \\
\hline \multicolumn{3}{|c|}{ Household size } \\
\hline $1-5$ & 54 & 30.0 \\
\hline $6-10$ & 105 & 58.3 \\
\hline $11-15$ & 13 & 7.2 \\
\hline $16-20$ & 8 & 4.4 \\
\hline \multicolumn{3}{|c|}{ Marital status } \\
\hline Single & 141 & 78.3 \\
\hline Married & 39 & 21.7 \\
\hline \multicolumn{3}{|l|}{ Education } \\
\hline No formal & 17 & 9.4 \\
\hline Primary & 25 & 13.9 \\
\hline Junior high & 30 & 16.7 \\
\hline Secondary & 35 & 19.4 \\
\hline Tertiary & 73 & 40.6 \\
\hline \multicolumn{3}{|l|}{ Income } \\
\hline$<1000$ & 80 & 44.4 \\
\hline 1000-2000 & 73 & 40.6 \\
\hline 2000-3000 & 20 & 11.1 \\
\hline $3000-4000$ & 3 & 1.7 \\
\hline $4000-5000$ & 4 & 2.2 \\
\hline
\end{tabular}

Note. $\$ 1=\mathrm{GH} \$ 3.89$ at the time of the survey.

observations. The rejection or otherwise of the hypothesis is therefore based on the significance of the chi square. Given that it is significant, the null hypothesis is rejected; otherwise, the null hypothesis is retained.

\section{Results and Discussions}

3.1. Socioeconomic Characteristics of the Respondents. Table 2 describes the socioeconomic characteristics of the respondents. The majority $(82.8 \%)$ of the respondents were females. This is not surprising considering the objective of the study, where, expectedly, women would provide more reliable information on consumption than males. The inclusion of the other $17.2 \%$ males could also offer an excellent crossreference for the information provided by the female since, in any case, both sex groups are involved in household consumption decisions. Over half (61.6\%) of the respondents are having ages greater than 39. Household size was also high among the respondents as majority of the respondents (58.3\%) have household size above the study region's mean of 5.8. Education was found to be high among the respondents.
TABLE 3: Local rice consumption pattern of households in the study.

\begin{tabular}{lcc}
\hline Categories & Frequency & Percentage \\
\hline Almost everyday & 35 & 19.4 \\
Twice a week & 75 & 41.7 \\
Once every week & 41 & 22.8 \\
Every 2 weeks & 8 & 4.4 \\
Once monthly & 2 & 1.1 \\
Occasionally & 19 & 10.6 \\
Total & 180 & 100 \\
\hline
\end{tabular}

While $90.6 \%$ had at least primary education, only $9.4 \%$ had no formal education. Mean household income distribution shows that the largest proportion (44.4\%) have incomes that are below $\mathrm{GH} \$ 1,000$ (US\$257) per month. Less than $5 \%$ had income above GH\$3,000 (US\$770).

3.2. Consumption Pattern of Local Rice. Rice is one of the major staples in the region like other parts of Ghana. As such, it was evident that $19.4 \%, 41.7 \%$, and $22.8 \%$ of the respondents indicated that they consume local rice daily, twice a week, and once every week, respectively (see Table 3). Although this does not provide evidence on the quantity of consumption, the high frequency of use by the respondents is a good signal of local rice consumption. That is, given all the necessary factors that drive the preference for consumption of domestic rice, the local rice industry right from production to processing/marketing could provide a great relief for the country. This is in recognition of the fact that rice importation is one of the leading contributors to Ghana's high import bill. Also, with the government's drive to enhance consumption of "made in Ghana" goods, improving consumers' preference, pattern, and frequency is necessary.

3.3. Factors Influencing Consumers' Preference for Local Rice. The results of the estimated Probit model of the factors influencing consumer preference for local rice are presented in Table 3. The Probit model is statistically significant at $1 \%$ level of significance as indicated by the likelihood ratio value $\left(\right.$ LR Chi $\left.{ }^{2}(11)=36.12 ; p \leq 0.001\right)$. The value of the Wald test $\left[\mathrm{Chi}^{2}(11)=28.52 ; p \leq 0.001\right]$ indicates that the estimates of the regression are different from zero. Moreover, the model correctly classified $74.31 \%$ of respondents among those who preferred local rice while $53.52 \%$ of the respondents were correctly classified among those who do not prefer local rice. Generally, demand is a function of price and income (however, price was excluded from the model due to the homogeneity of the price of rice across the study communities; thus, the price was almost similar). However, aside from these two, some other factors including socioeconomic factors and product description or quality could influence demand. Therefore, Table 4 provides the determinants of consumer preference of local rice in the Upper East Region, considering these three classes of preference drivers. Classical microeconomics provides that, for normal goods, demand is a positive function of income. That is, as income increases, more of a product is demanded. However, the reverse is 
TABLE 4: Factors influencing preference for local rice.

\begin{tabular}{|c|c|c|c|}
\hline Variable & Coefficient & SE & Marginal effects \\
\hline \multicolumn{4}{|l|}{ Socioeconomic factors } \\
\hline Income & $-0.00036^{* *}$ & 0.00017 & -0.00039 \\
\hline Age & $0.07094^{*}$ & 0.00591 & 0.026727 \\
\hline Age squared & $-0.00074^{*}$ & 0.00021 & -0.000279 \\
\hline $\operatorname{sex}$ & $0.04537^{* *}$ & 0.02135 & 0.03451 \\
\hline Marital status & $-0.39908^{* *}$ & 0.16697 & 0.15036 \\
\hline Household size & -0.09648 & 0.04284 & 0.03635 \\
\hline Number of years in education & -0.01916 & 0.01809 & 0.00072 \\
\hline \multicolumn{4}{|l|}{ Quality factors } \\
\hline Grain size & 0.08356 & 0.11906 & 0.03148 \\
\hline Texture & 0.19185 & 0.11891 & 0.07228 \\
\hline Cleanness & $0.35454^{* *}$ & 0.12557 & 0.05822 \\
\hline Aroma & $0.41352^{*}$ & 0.11715 & 0.08045 \\
\hline Packaging & $0.44286^{*}$ & 0.13009 & 0.16685 \\
\hline Constant & 0.14701 & 1.53889 & \\
\hline \multicolumn{4}{|l|}{ LR Chi2 (11) [36.12; $p \leq 0.001]$} \\
\hline Wald Chi2 (11) $[28.52 ; p \leq 0.001]$ & $74.31 \%$ & & \\
\hline \multicolumn{4}{|l|}{ Sensitivity (\% correctly classified among local rice preference group) } \\
\hline Specificity (\% correctly classified among nonlocal rice preference group) & $53.52 \%$ & & \\
\hline Total correctly classified (\%) & $66.11 \%$ & & \\
\hline
\end{tabular}

$*$ and $* *$ indicate significance at $1 \%$ and $5 \%$ levels, respectively.

the case in this study. As income increases, preference for local rice decreases. It is generally perceived in Ghana that local rice is for the "poor households" and "rich households" tend to consume imported rice which is usually described as "perfumed or polished rice." It is no surprise that the study found an inverse relationship between preference and income, as, generally, the tastes of high-income earners are most likely to orient towards foreign goods than local goods. It is, therefore, important that incentives be provided for the production of local rice to encourage high-income people into its consumption.

With regard to the socioeconomic factors, all except education had a significant effect on consumer preference. Although not significant, the negative marginal effect of education implies that the less educated prefer local rice, consistent with prior knowledge of the characteristics of rice consumers in the country. The positive and negative significance of age and age squared, respectively, means that the elderly have a higher preference for local rice than the younger household heads. Observations indicated that the youths consume more of imported rice than local rice due to the prestige that is usually associated with the former. The youths generally would not want their colleagues to see them consume local rice. This is contrary to the study of Dansoabbeam et al. [16] who estimated that local rice consumption is negatively related to age. The coefficient of sex was positive which means that the probability of preferring local rice was higher for female respondents than male respondents.
This is a significant finding considering the core role women play in household food choice and provision as indicated by Demont and Ndour [29]. Thus, it is the central role of women in the Ghana to put food on the table for the men. Contrary to expectation, the married have less probability of preferring local rice to imported rice. A chisquare analysis by Alhassan et al. [30] found that the married have a higher preference for imported rice than local rice. Ogundele [31] also found that sex and age have a significant positive effect on preference for local rice while marital status had a significant negative effect on preference for local rice in Nigeria.

Among the quality factors, aroma, good packaging, and cleanness all had a significant positive marginal effect on preference for local rice. Grain size and texture were found to have no significant effect on consumer preference. Aromatic rice, also called fragrant or perfumed rice, is characterized by the presence of baked bread-like flavour that smells and tastes so good after cooking [32]. Aromatic rice has been cultivated for centuries in Asia and is highly prized across the globe [33]. Fragrant rice varieties such as Jasmine and Basmati are popular not only in Ghana, but also in the African continent, Europe, and the USA, making them command a considerable proportion of the global rice market [34]. Asante et al. [35] noted breeding for fragrant is becoming increasingly popular in the African rice breeding programmes. It is, therefore, not surprising that the aroma quality traits of rice positively influence consumers' preference for local rice. Consumers are 
TABLE 5: Result of the ranked attributes households consider in purchasing rice.

\begin{tabular}{lcc}
\hline Traits & Mean rank & Rank \\
\hline Good-looking grains & 2.71 & 1st \\
Cleanness & 2.73 & 2nd \\
Packaging & 2.93 & $3 \mathrm{rd}$ \\
Taste & 3.76 & 4 th \\
Texture & 3.81 & 5 th \\
Aroma & 3.81 & 6 th \\
Ease of cooking & 3.96 & 7 th \\
Volume of expansion & 4.32 & 8 th \\
Nutritional value & 4.55 & 9 th \\
Relative price & 4.63 & 10 th \\
\hline
\end{tabular}

Kendall's Coefficient of Concordance $(W)=0.382$, Chi-Square $=213.991$ $(5)^{* * *} . * * *$ denotes significance at $1 \%$ level.

much particular about instances of finding foreign materials or matter in the local rice. That is, the presence of foreign matter and other debris in the rice makes it unattractive to them. The implication is that if the local rice can be processed with no foreign matter or debris, the probability that more consumers would switch to its consumption would increase. This provides a clear policy direction. Consumers who indicated consent of good packaging and aroma also have a higher probability to local rice preference. Abubakar et al. [36] noted that texture, grain size, aroma, taste, and colour are some of the key traits consumers consider in their choice of rice, whether local or imported. This supports a statement by a respondent in Alhassan et al. [30] that "the aroma emanating from the cooked imported rice instigate me to eat more."

3.4. Consumers' Expected Traits of Local Rice. Aside from the econometric estimation provided above, consumers were asked to rank the attributes of rice listed in Table 1 in order of importance. Kendall's coefficient of concordance was used to rank the traits consumers consider in their preference for locally produced rice. From Table 5 , the good-looking grains of rice were ranked as the most influential attribute with a mean rank of 2.71. Mottaleb and Mishra [19] noted that visual appearance of the rice grain is an outstanding quality that influences consumers' purchasing decision. This was followed by the cleanness and good packaging of rice with a mean rank of 2.73 and 2.93 , respectively.

Taste, texture, and aroma were ranked 4 th, 5 th, and 6 th, respectively. Abubakar et al. [36] reported that texture is the most important attribute, followed by grain size, taste, aroma, and colour. The least ranked traits are nutritional value and relative price with a mean score of 4.55 and 4.63 , respectively. Kendall's concordance coefficient $(W)$ obtained in the analysis is 0.382 , and the chi-square statistics is also 213.991 with 5 degrees of freedom and asymptotic significance of 0.000 . Kendall's coefficient $(W)$ estimated indicates that there is $38.2 \%$ agreement by the respondents on the ranking of the attributes. The low ranking could be due to the complexity of attributes to local rice consumption by the respondents.

\section{Conclusions and Policy Recommendations}

Investment in the production of rice in Africa in general and Ghana, in particular, is a necessary condition to meet the country's consumption demand for rice, raise the standard of living of the producers, and minimize food insecurity. However, it is sufficiently important to pay attention to quality standards that meet the preferences of the consumers. This study assessed the factors influencing consumers' preference for domestically produced rice and the factors inhibiting the patronage of the local rice. From the study, it is concluded that local rice consumption is higher in the study area, at least relative to other studies in other parts of the country. Socioeconomic factors, as well as quality factors, remained significant in influencing consumers' preference for local rice. However, the study found a deviation of the classical effect of income on demand.

The positive implications of some quality attributes on consumers' preference for local rice suggest that investment in postharvest rice quality is a necessary first step that will enable domestically produced rice to compete against the imported rice successfully. Focusing on quality standards of local rice will boost the preference for local rice which will make the local rice market less vulnerable to the vagaries of the international rice market. Thus, strengthening the local rice markets has the great potential of enhancing the livelihoods of local producers and raise the rural household food security status. In Ghana, about $50 \%$ of rice consumed annually is imported from the international market. With such large dependency, the country's macroeconomic balances are adversely affected, and the market is also exposed to global market shocks, with economic and political implications such as the food crisis events in 2008. Moreover, good-looking grains remained the priority of consumers when buying rice which still points to the quality standards when adding value to the local rice. Therefore, increased investment in the rice value chain, particularly at the processing stage, is highly recommended to make the grain more attractive to consumers. Furthermore, an advertisement could be one of the tools to push the demand for local rice. Norman et al. [37] noted that advertisement could serve as a complement to the product being marketed and affects the demand for the good without changing the underlying preference for the product. Consumers usually place a greater value on a product being advertised because they enjoy knowing that the product they buy is being recognized by many on television, radio, and billboards. It is, therefore, incumbent on the government to create massive awareness through advertisement to enhance the purchase of local rice. Moreover, the study recommends the inclusion of market research on the consumer and farmer preferences in the country's Research and Development ( $R$ \& D) programmes to minimize the incidence of hunger, enhance food security, and improve rural livelihoods. Nevertheless, there is a general trade-off between quality through value-addition and affordability. While the quality of the local rice needs to be enhanced to remain competitive to the imported rice, the price needs to be cheap since consumers are usually price-sensitive. The study, therefore, recommends that future studies should consider consumers' willingness to 
pay for the upgrade of local rice. This will inform policies on rice value chain regarding the issues of quality and price.

\section{Conflicts of Interest}

The authors of this paper declare that there are no conflicts of interest.

\section{References}

[1] S. Mohanty, "Trends in global rice consumption," Rice Today, vol. 12, no. 1, pp. 44-45, 2013.

[2] FAO (Food and Agriculture Organization) "Rice market monitor", FAO Trade and Markets, Division, Rome, vol. 15, No. 4, 2012.

[3] Africa Rice Center (WARDA), Africa Rice Trends: overview of recent developments in the sub-Saharan Africa rice sector. Africa Rice Center Brief. .Africa Rice Center (WARDA), Cotonou, Benin, 2007. http://www.warda.org.

[4] IRRI (International Rice Research Institute) (2012) World Rice Statistics. IRRI, Los Banos, 2012. http://www.irri.org. Accessed 25 Nov 2016.

[5] M. Demont, "Reversing urban bias in African rice markets: a review of 19 national rice development strategies," Global Food Security, vol. 2, no. 3, pp. 172-181, 2013.

[6] S. Nasrin, J. B. Lodin, M. Jirström, B. Holmquist, A. A. Djurfeldt, and G. Djurfeldt, "Drivers of rice production: evidence from five Sub-Saharan African countries," Agriculture and Food Security, vol. 4, no. 1, article no. 12, 2015.

[7] V. S. E. Troare, Marker assisted selection for resistance to rice yellow mottle virus in farmers' preferred rice varieties in Burkina Faso. A PhD thesis, West Africa Center for Crop Improvement (WACCI), School of Agriculture, College of Agriculture and Consumer Sciences, University of Ghana, Legon, 2013.

[8] M. Hossain, "Rice in Africa: can rice help reduce hunger and poverty in sub-Saharan Africa?" Rice Today, vol. 5, no. 1, pp. 4150, 2006.

[9] V. Balasubramanian, M. Sie, R. J. Hijmans, and K. Otsuka, "Increasing rice production in Sub-Saharan Africa: challenges and opportunities," Advances in Agronomy, vol. 94, pp. 55-133, 2007.

[10] MOFA (Ministry of Food and Agriculture), Agriculture in Ghana. Facts and figures (2014). Statistics, Research and Information Directorate (SRID), MoFA, Accra, 2015.

[11] E. M. Kwofie, M. Ngadi, and A. Mainoo, "Local rice parboiling and its energy dynamics in Ghana," Energy for Sustainable Development, vol. 34, pp. 10-19, 2016.

[12] W. Dogbe, S. O. Abebrese, R. Owusu, B. Inusah, and A. Danaa, "Performance of eleven introduced improved lowland rice varieties in the northern Savanna zones of Ghana," African Journal of Agricultural Research, vol. 11, no. 5, pp. 324-329, 2016.

[13] D. P. Patel, A. Das, G. C. Munda, P. K. Ghosh, J. S. Bordoloi, and M. Kumar, "Evaluation of yield and physiological attributes of high-yielding rice varieties under aerobic and flood-irrigated management practices in mid-hills ecosystem," Agricultural Water Management, vol. 97, no. 9, pp. 1269-1276, 2010.

[14] P. Gibbon, Commodities, donors, value-chain analysis and upgrading. International Center for Trade and Sustainable Development (ICTSD). A contributed paper prepared for UNCTAD 2003. http://www.ictsd.org/downloads/2008/08/ gibbon.pdf, 2004.

[15] M. Addison, P. Sarfo-Mensah, and S. E. Edusah, "ssessing Ghana's initiative of increasing domestic rice production through the development of rice value chain," Global Journal of Agricultural Economics, Extension and Rural Development, vol. 3, no. 4, pp. 230-237, 2015.

[16] G. Danso-abbeam, M. Armed, and F. Baidoo, "Determinants of consumer preference for local rice in Tamale Metropolis, Ghana," International Journal of Education and Social Science, vol. 1, no. 2, pp. 114-122, 2014.

[17] Y. S. Tey and M. Brindal, "Adapting importation policy to global commodity markets: implications of rice import allocation in Singapore," Mitigation and Adaptation Strategies for Global Change, vol. 19, no. 8, pp. 1277-1293, 2014.

[18] K. J. Lancaster, "A new approach to consumer theory," Journal of Political Economy, vol. 74, no. 2, pp. 132-157, 1966.

[19] K. A. Mottaleb and A. K. Mishra, "Rice consumption and graintype preference by household: A Bangladesh case," Journal of Agricultural and Applied Economics, vol. 48, no. 3, pp. 298-319, 2016.

[20] R. Aidoo, G. K. Nurah, S. C. Fialor, and K. Ohene-Yankyera, "Determinants of Daily consumption expenditure in urban communities in Southern Ghana," Journal of Science and Technology, vol. 29, no. 1, pp. 87-96, 2009.

[21] R. Rachmat, R. Thahir, and M. Gummert, "The empirical relationship between price and quality of rice at market level in west Java," Indonesian Journal of Agricultural Science, vol. 7, no. 1, pp. 27-33, 2006.

[22] C. Diako, E. Sakyi-Dawson, B. Bediako-Amoa, F. K. Saalia, and J. T. Manful, "Consumer perceptions, knowledge and preferences for aromatic rice types in Ghana," Nature and Science, vol. 8, no. 12, 2010.

[23] M. A. Fitzgerald, "Characteristics and quality requirements," in Cereal grains: assessing and managing quality, C. W. Wrigley and I. L. Batey, Eds., Woodhead Publishing, Cambridge, UK, 2010.

[24] M. Diagne, M. Demont, and M. Ndour, "What is the value of rice frangrance? Consumer Evidence from Senegal," African Journal of Agricultural and Resource Economics, vol. 12, no. 2, pp. 99-110, 2017.

[25] A. Naseem, S. Mhlanga, A. Diagne, P. Y. Adegbola, and G. S.K. Midingoyi, "Economic analysis of consumer choices based on rice attributes in the food markets of West Africa-the case of Benin," Food Security, vol. 5, no. 4, pp. 575-589, 2013.

[26] J. J. Louviere, D. A. Hensher, and J. Swait, Stated Choice Methods: Analysis and Application, Cambridge University Press, 2000.

[27] D. Caleb and A. Ramatu, "Factors influencing participation in rice development projects: the case of smallholder farmers in Northern Ghana," International Journal of Development and Economic Sustainability, vol. 1, no. 2, pp. 13-27, 2013.

[28] P. Legendre, "Species associations: The Kendall coefficient of concordance revisited," Journal of Agricultural, Biological, and Environmental Statistics, vol. 10, no. 2, pp. 226-245, 2005.

[29] M. Demont and M. Ndour, "Upgrading rice value chains: Experimental evidence from 11 African markets," Global Food Security, vol. 5, pp. 70-76, 2015.

[30] H. Alhassan, T. Frimpong, and A. S. Mohammed, "Do Ghanaian rural consumers prefer imported rice to local rice? Evidence from Akuapem North Municipality," Applied Research Journal, vol. 1, no. 3, pp. 24-34, 2015. 
[31] O. Ogundele, "Factors influencing consumers preference for local rice in Nigeria," African Journal of Marketing Management, vol. 6, no. 4, pp. 49-55, 2014.

[32] M. Calingacion, A. Laborte, A. Nelson et al., "Diversity of global rice markets and the science required for consumer-targeted rice breeding," PLoS ONE, vol. 9, no. 1, Article ID e85106, 2014.

[33] T. Itani, M. Tamaki, Y. Hayata, T. Fushimi, and K. Hashizume, "Variation of 2-acetyl-1-pyrroline concentration in aromatic rice grains collected in the same region in Japan and factors affecting its concentration," Plant Production Science, vol. 7, no. 2, pp. 178-183, 2004.

[34] P. Bhattacharjee, R. S. Singhal, and P. R. Kulkarni, "Basmati rice: A review," International Journal of Food Science \& Technology, vol. 37, no. 1, pp. 1-12, 2002.

[35] M. D. Asante, M. J. Kovach, L. Huang et al., "The genetic origin of fragrance in NERICA1," Molecular Breeding, vol. 26, no. 3, pp. 419-424, 2010.

[36] Y. Abubakar, G. Rezai, M. N, Shamsudin., and Z. Mohamed, "Malaysian consumers' demand for quality attributes of imported Rice," Australian Journal of Basic and Applied Sciences, vol. 9, no. 37, pp. 317-322, 2015.

[37] G. Norman, L. Pepall, and D. Richards, "Generic product advertising, spillovers, and market concentration," American Journal of Agricultural Economics, vol. 90, no. 3, pp. 719-732, 2008. 


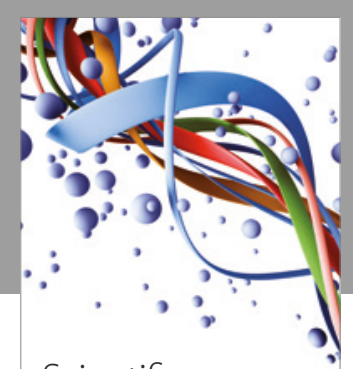

Scientifica
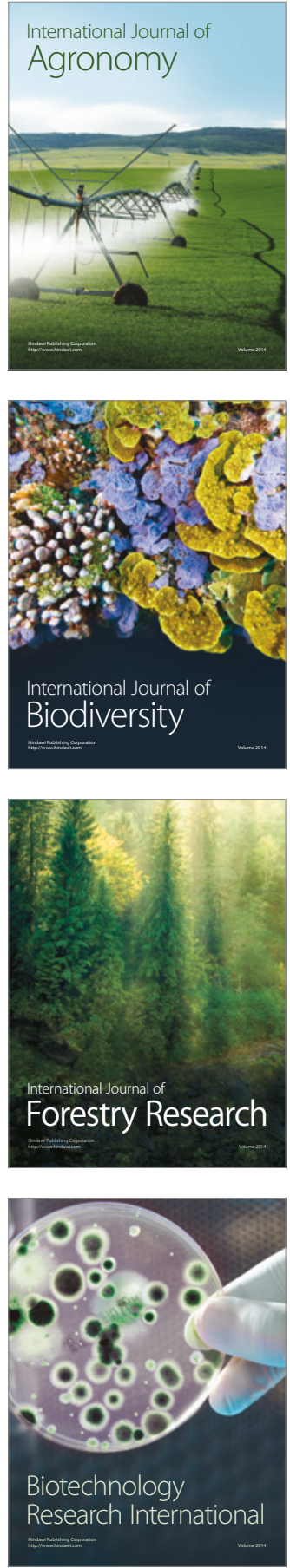
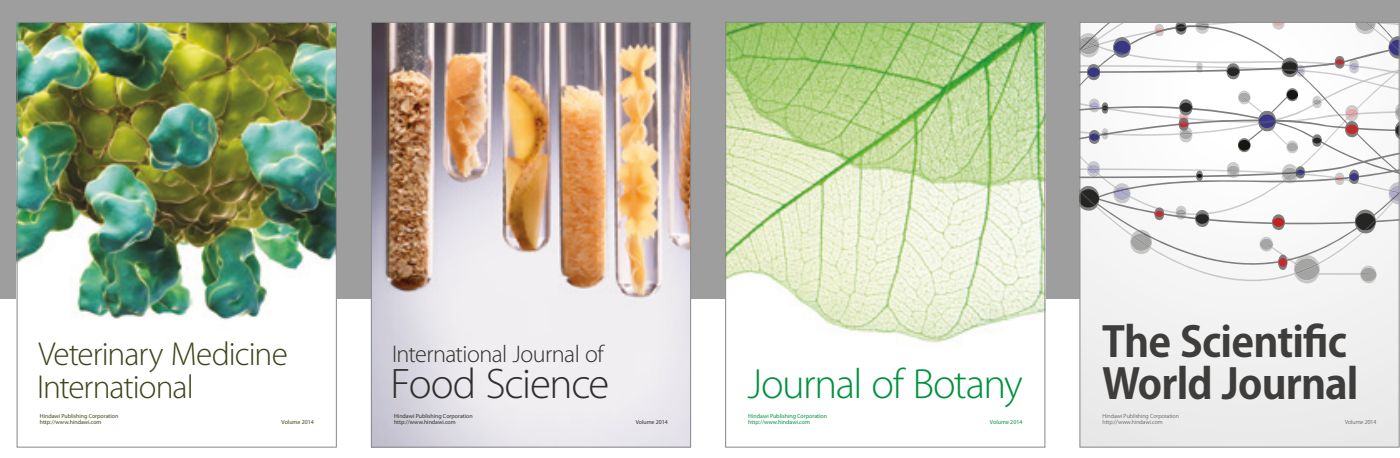

The Scientific

\section{World Journal}

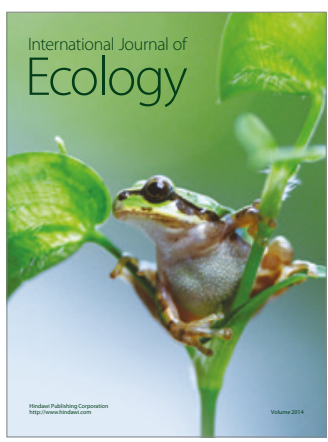

\section{Hindawi}

Submit your manuscripts at

https://www.hindawi.com
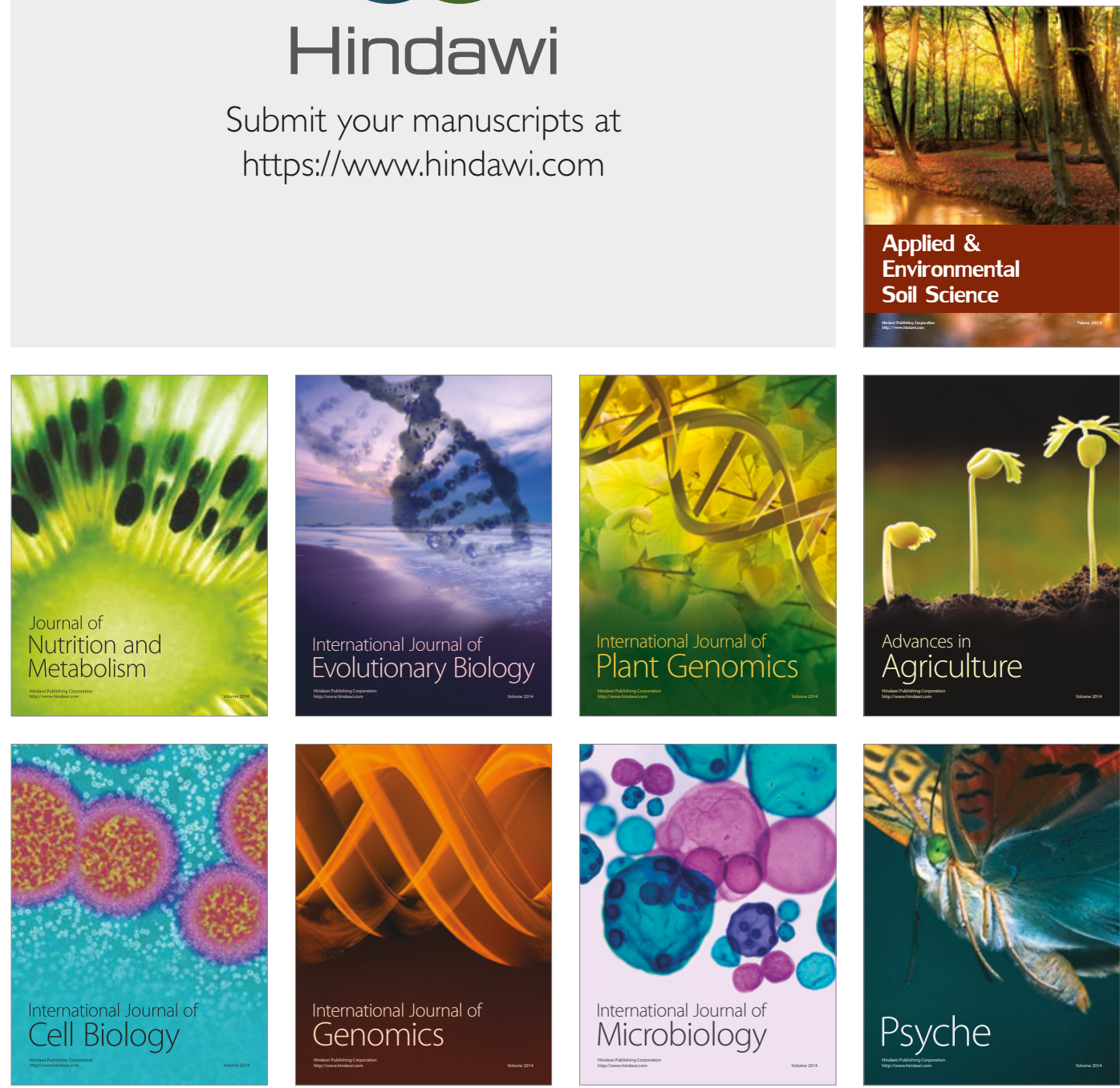

hternational Journal of Microbiology
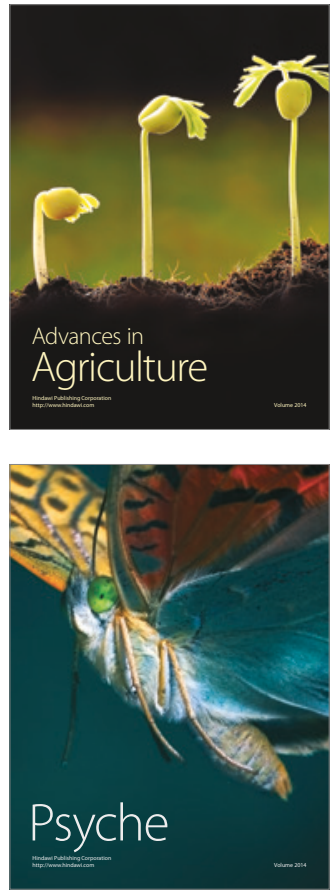